UDC: 821.134.2(82).09-31 Cortázar J. DOI: https://doi.org/10.18485/hispserb.2019.2.ch16

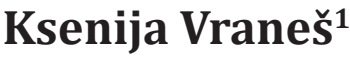 \\ Universidad de Belgrado \\ Serbia
}

\title{
LA POÉTICA EXPLÍCITA DE JULIO CORTÁZAR
}

\begin{abstract}
Resumen
Julio Cortázar expone su poética explícita en numerosos ensayos, estudios críticos y teóricos que escribía y publicaba durante toda su vida. La cuestión compleja de la relación entre la realidad y la literatura fantástica es un tema de suma importancia tanto para la creación literaria de Cortázar, como para la literatura del así llamado "boom" hispanoamericano. Cortázar se opone al realismo decimonónico que no alcanza el lado más profundo y secreto de la vida, y él anuncia una idea de la realidad total en la literatura. En los ensayos de Cortázar la cuestión de la realidad se relaciona estrechamente con diferentes maneras de su representación literaria en cuentos y novelas. A través de una serie de comparaciones acertadas y vivas, Cortázar elabora su teoría del cuento breve y de la novela. Aunque insiste en la responsabilidad del escritor en cuanto al éxito de su obra, Cortázar señala la importancia del papel de un lector activo. En este sentido, la cuestión del compromiso social de la literatura surge como un tema central. Cortázar sostiene que una obra de arte verdaderamente revolucionaria no tiene que dirigirse al contenido político y revolucionario, sino a la innovación literaria. Según Cortázar, la posibilidad de escribir sobre temas eróticos presenta también una suerte de revolución literaria que debería realizarse para que la literatura hispanoamericana abarque todos los aspectos de la condición humana y para que se emancipe en la literatura la totalidad de la vida social humana.

Palabras clave: Julio Cortázar (1914-1984), poética explícita, cuento, novela, revolución literaria.
\end{abstract}

\footnotetext{
${ }^{1}$ ksenija.m.vranes@gmail.com
} 
En el público literarioy lector más amplio Julio Cortázar es conocido como uno de los mejores cuentistas y novelistas hispanoamericanos, quizás uno de los mejores del mundo. En el siguiente paso, Cortázar es reconocido como el autor de obras experimentales e híbridas, como un amante de la vida de cada día, los "pequeños" temas y grandes problemas metafísicos, como un ardiente luchador por libertades políticas y derechos humanos. Algunos lectores saben que Cortázar escribió un drama y varios libros de poemas, pero poco se sabe que durante toda su vida Cortázar se dedicaba a la crítica literaria y que escribió un gran número de textos teóricos y (auto)poéticos. No obstante, esto no quiere decir que su contribución en este ámbito sea insignificante, sino que sus escritos puramente teóricos en los que expone su poética explícita son incomparablemente menos estudiados que los elementos o puntos autopoéticos en la obra artística de Cortázar.

Entre los escritos poéticos de Cortázar se encuentran obras ensayísticas independientes y complejas, como "Teoría del túnel” (1947), ensayos teóricos y de historia literaria, como son "Situación de la novela" (1950), "El escritor y el lector en América Latina" (1978) o "Para una poética" (1954), transcriptos de sus discursos y conferencias, como, entre otros, "Algunos aspectos del cuento" (1962-1963), "Escribir para el pueblo" (1979), "La literatura latinoamericana a la luz de la historia contemporánea" (1979-1980), "Los caminos de un escritor" (1980), "Realidad y literatura en América Latina" (1980), "El intelectual y la política en Hispanoamérica" (1983), "El estado actual de la narrativa en Hispanoamérica" (1983), polémicas con otros críticos y escritores, como la famosa disputa con Óscar Collazos titulada "Literatura en la revolución y revolución en la literatura", y unos escritos dentro de libros-almanaques de Cortázar, La vuelta al día en ochenta mundos (1967) y Último round (1969).

La cuestión de la relación entre la literatura y la realidad, o más precisamente, entre la literatura fantástica y la realidad, representa uno de puntos de partida para la poética de Cortázar. El escritor se opone a la concepción tradicional de realismo que califica de falso y, según su opinión, determinado por "las relaciones de causa a efecto, de psicologías definidas, de geografías bien cartografiadas" (Cortázar 1971: 404). Cortázar sostiene que la imagen de realidad concebida de ese modo es demasiado concreta y marcada por el aspecto sociocultural, los adjetivos que en este caso adquieren una connotación especialmente negativa como se trata de una representación de realidad extremadamente estrecha y fragmentaria. Tal comprensión de la naturaleza de la realidad Cortázar la considera superficial o "bastante agropecuaria" (Cortázar 1970: 46) 
porque no alcanza el "otro orden más secreto y menos comunicable" (Cortázar 1971: 404). Cortázar considera que "la literatura es una empresa de conquista verbal de la realidad" (Cortázar 1994a: 217), una realidad absolutamente mítica y mucho más compleja de lo que se considera en general (Cortázar 1970: 48). Por lo tanto, para penetrar debajo de la superficie del contexto sociocultural, la literatura debe separarse de la concepción tradicional de la literatura realista decimonónica que pintaba casi exclusivamente la realidad social inmediata y obvia. Para Cortázar la literatura que presenta otras facetas de realidad no es necesariamente fantástica. Por el contrario, el escritor argentino afirma que "la literatura es siempre una expresión de la realidad, por más imaginaria que sea" (Cortázar 1982: 5).

Es por esa razón que Cortázar a menudo niega escribir la asíllamada literatura fantástica, sino reitera que él escribe una literatura total que contiene todos los aspectos de la realidad. Por lo tanto, la literatura fantástica a Cortázar le parece más actual que la literatura orientada hacia la realidad visible (Cortázar 1970: 57), porque se ocupa de los lados profundos u ocultos de la vida humana. La literatura fantástica entendida de este modo no se puede acusar de ser escapista ya que su objetivo no es alejar al hombre de su entorno inmediato, entretenerlo y aliviarle su existencia de esta manera, sino, completamente opuesto a la opinión general, la literatura fantástica revela la cara secreta del mundo que nos rodea (Cortázar 1970: 57-58, 66). Además de eso, añade Cortázar (1970: 66), existe un gran número de lectores

a quienes el "reconocimiento" entre su realidad y el producto literario no les preocupa tanto como el descubrimiento de nuevas fórmulas, ángulos, desplazamientos enriquecedores de la realidad. (...) Leemos novelas para saciar nuestra sed de extrañamiento, y lo que les agradecemos es que nos abran, sin traicionar la realidad profunda, otras capas y otras facetas de la realidad que jamás descubriríamos en lo cotidiano.

Para explicar esta concepción de realidad compleja caracterizada por las relaciones profundas pero difíciles de percibir, Cortázar utiliza la noción de la "figura". En los estudios dedicados al tema de la figura en las ficciones de Cortázar², se da por sentado que la noción de la figura

\footnotetext{
${ }^{2}$ La noción de la figura se presenta como uno de los conceptos centrales en los cuentos y novelas de Cortázar, y como consecuencia numerosos críticos han prestado mucha atención a la importancia de la figura en las ficciones de Cortázar: p. ej. Hartmann 1969; Filer 1970: 72-73; Francescato 1972: 369-370; Dellepiane 1975: 27-28; Scholz 1977:
} 
es una invención original del autor argentino. No obstante, en 1938 el famoso filólogo alemán, Erich Auerbach, publicó un ensayo intitulado "Figura" donde examinó la noción medieval de la figura que se remonta a los principios del cristianismo y San Pablo de Tarso (Auerbach 1984: 49-60). La idea de la figura, sin embargo, adquiere una importancia particular dentro del contexto de la así llamada interpretación figural de la Biblia (the figural interpretation, en inglés) utilizada por los filósofos cristianos medievales Tertuliano y San Agustín (Auerbach 1984: 28-49). La interpretación figural, según Auerbach (1984: 36-53), representa una manera de interpretar los acontecimientos o personas del Antiguo Testamento, por ejemplo, el sacrificio de Isaac, como las prefiguraciones o predicciones de la venida o el sacrificio de Cristo, u otros acontecimientos del Nuevo Testamento.

Por otro lado, Cortázar formula la noción de la figura en su primera novela publicada, Los premios en 1960, luego la expone más en detalle en la entrevista con Luis Harss en 1966 (v. Harss 1966: 278), para definirla finalmente en su ensayo "Cristal con una rosa adentro" publicado en 1969 dentro del libro-almanaque Último round (v. Cortázar 1974c). No obstante, Cortázar no menciona a Auerbach, a Tertuliano o a San Agustín en cualquiera de estos textos, pero no sería raro que un lector de libros tan versátiles y numerosos como Cortázar topara con la noción medieval de la figura. Al mismo tiempo, la idea de la figura como lo entiende Auerbach se asemeja en gran medida con la noción de la figura utilizada por Cortázar. Bajo la idea de la figura, Cortázar entiende una serie de elementos aparentemente inconexos que desvelan un sentido más profundo, o, en las palabras del argentino mismo:

no es infrecuente que en el sujeto dado a ese tipo de distracciones (lo que se llama papar moscas) la presentación sucesiva de varios fenómenos heterogéneos cree instantáneamente una aprehensión de homogeneidad deslumbradora. En mi condición habitual de papador de moscas puede ocurrirme que una serie de fenómenos iniciada por el ruido de una puerta al cerrarse, que precede o se superpone a una sonrisa de mi mujer, al recuerdo de una callejuela en Antibes y a la visión de una rosa en un vaso, desencadene una figura ajena a todos sus elementos parciales, por completo indiferente a sus posibles nexos asociativos o causales, y proponga - en este instante fulgural e irrepetible y ya pasado y oscureciendo - la entrevisión de otra realidad en la que eso que para mí

97; Boldy 1980: 23; Sicard 1981: 229; Goloboff 1986: 241-243; Kerr 1998: 97; Bongers 2000: 170-187; Lobo Pedreros 2004: 132-135; Brenes Reyes 2011: 22; Zeppegno 2012: 334-336; Preciado 2014; Dickov 2015: 113. 
era ruido de puerta, sonrisa y rosa constituye algo por completo diferente en esencia y significación. (Cortázar 1974c: 127-128, subrayado por K.V.)

No obstante, "la condición habitual de papador de moscas" a la que se refiere Cortázar parece ser un estado innato para el escritor argentino. En la entrevista con Omar Prego (1985: 88), Cortázar afirma que la noción de la casualidad que se encuentra en el centro de la concepción de figura, le interesaba desde su más temprana infancia:

Muchas cosas que la gente atribuía a casualidades, cuando usaban la palabra casualidad para explicar o explicarse ese tipo de 'coincidencias' que se daban en la vida, yo sentía de manera intuitiva que decir 'casualidad' o 'coincidencia' no explicaba absolutamente nada. Esas cosas que se producían y parecían coincidencias o casualidades yo las sentí siempre desde muy niño como respondiendo a un sistema de leyes diferente al sistema de leyes aceptable y conocible por todo el mundo. [...] Yo sentía que cuando se producía un elemento $\mathrm{A}$, seguido de un elemento $\mathrm{B}$ - que era lo que la gente llamaría una coincidencia o una casualidad - había un tercer elemento $\mathrm{C}$, que podía ser un elemento alcanzable, comprensible o no; pero de todas maneras yo sentía que el triángulo, que la figura, se cerraba. Nunca había A y B, siempre había A y B que despertaban, que creaban la noción de C. (Prego 1985: 88)

Para ampliar la idea de figura y explicar su funcionamiento, Cortázar utiliza una serie de metáforas (p. ej. las barajas, el coágulo, la cristalización, el caleidoscopio, el mandala) de las cuales destaca la imagen de constelación (v. Salmones Castaneda 2013: 163). Igual que la noción de la figura, Cortázar introduce el motivo de constelación por primera vez en Los premios en 1960, pero en la entrevista con Luis Harss en 1966 aclara que fue una frase de Jean Cocteau que inspiró su concepto de constelación: "una frase de Cocteau, según la cual las estrellas individuales que forman una constelación no tienen idea de que forman una constelación." (Harss 1966: 278). ${ }^{3}$ Luego, en la mencionada conversación con Omar Prego (1985: 135), Cortázar explica que "quien tiene sentido del humor tiene siempre la tendencia a ver en diferentes

\footnotetext{
${ }^{3}$ Debería mencionarse que la idea de constelación de Cortázar es análoga a la concepción de constelación tal como la define Walter Benjamin en su Libro de los pasajes (Das Passagen-Werk) escrito entre 1927 y 1940, pero publicado por primera vez en 1982. Mientras Ames Casas (2011: 36-39) estudió en profundidad las similitudes entre los conceptos de constelación de Benjamin y de Cortázar, Salmones Castaneda (2013: 43) y Batres Cuevas (2013: 267-271) se dedicaron a la ocurrencia de las ideas semejantes en otros autores contemporáneos (p. ej. Nathalie Sarraute o Philippe-Alain Michaud).
} 
elementos de la realidad que lo rodea una serie de constelaciones que se articulan y que son, en apariencia, absurdas."

De hecho, tanto la idea de constelación, como la concepción de la figura son de suma importancia para la obra de Cortázar porque ofrecen la posibilidad para esclarecer la estructura de la narrativa de Cortázar supuestamente caótica y fragmentaria. La figura representa un vínculo entre, por un lado, la comprensión metafísica de la realidad por parte de Cortázar como un grupo de los elementos aparentemente inconexos, y, por otro lado, las maneras de organizar los contenidos o las estructuras de los cuentos y novelas de Cortázar aparentemente igual de inconexas. Los contenidos y las estructuras de los cuentos y novelas de Cortázar muy a menudo parecen caóticos o incoherentes porque ellos, de hecho, representan la materialización de la noción de la figura.

La noción de figura no es la única en la poética explícita de Cortázar que se refiere al cuento y a la novela. De hecho, el acto de contrastar estas dos formas literarias representa uno de los temas constantes del argentino. Para Cortázar, el cuento es similar a una fotografía por «el espacio» limitado que ocupa y por la cantidad de tiempo que presenta, y él insiste que la limitación física es uno de sus rasgos fundamentales (Cortázar 1971: 406). Por otro lado, la novela se asemeja a una película, lo que se puede entender de dos modos: bien como una obra de arte audiovisual que incluye un espacio y un período de tiempo significativamente mayores, o bien como un conjunto mayor compuesto de una multitud de fotogramas o cuentos (Cortázar 1971: 406). Insistiendo, por otra parte, en la duración mucho más larga de la narración que la novela ofrece, Cortázar compara la tarea del novelista con una victoria por puntos en el boxeo, donde ningún golpe singular sea decisivo, sino la suma de todos los golpes gana la victoria. Siguiendo esta analogía, el cuento representa la victoria por nocaut donde el boxeador o el escritor, tiene solo una oportunidad para dar el golpe decisivo (Cortázar 1971: 406-407). Las comparaciones de Cortázar entre novelas y cuentos indudablemente son muy interesantes e imaginativas, pero su particular importancia se encuentra en el hecho de que ellas presentan un testimonio sobre la actitud del escritor argentino hacia escritos teóricos y sobre su modo de escribirlos. El estilo que Cortázar utiliza en sus escritos teóricos y críticos revela su falta de entusiasmo por un discurso completamente teórico y muy serio, su lado travieso, divertido, un poco irónico y autocrítico, y su propensión a lo cotidiano y la cultura popular.

De este modo, extendiendo la idea de las limitaciones del cuento que, al mismo tiempo, tiene una fuerza atrayente impresionante, Cortázar 
(1971: 408-409) lo compara con un imán, un núcleo, un sol. Las razones de estas comparaciones se encuentran en el hecho de que el argumento de un cuento tiene que irradiar una atracción tan magnética que logra mantener juntos todos sus elementos (Cortázar 1971: 408-409). Por eso dice que el cuento es "una especie de apertura"4 y "una explosión que abre de par en par una realidad más amplia" (Cortázar 1971: 406). Un pequeño tema en el cuento abre la ventana hacia los conocimientos más profundos, por lo tanto, se puede decir que el cuento "trabaja[r] en profundidad, verticalmente" (Cortázar 1971: 407). Por consecuencia, Cortázar compara el cuento con un poema o con la música jazz ${ }^{5}$ (Cortázar 1974a: 78-79). A parte de la semejanza que Cortázar reconoce en la necesidad de crear tensión, ritmo y una pulsación interna del texto, el argentino afirma que "la tendencia metafórica es lugar común del hombre, y no actitud privativa de la poesía" (Cortázar 1994b: 267), y, por lo tanto, presente en la narrativa también.

Así que no es sorprendente que Cortázar considere que la poesía en la novela presenta una característica de la época literaria a la que pertenece (Cortázar 1994a: 228) y que, según su opinión, la novela no se puede determinar en cuanto al género literario. Según su punto de vista, la novela no se puede reducir a las reglas y leyes literarias porque la novela es "la cosa impura, el monstruo de muchas patas y muchos ojos, mezcla de heterogeneidades, grifo convertido animal doméstico. Todo vale allí, todo se aprovecha y confunde." (Cortázar 1994a: 228). Para construir la novela de la nueva época, Cortázar cree que todas las reglas y los principios de las épocas anteriores deben ser destruidos, pero esta demolición no es destructiva porque, como él dice en "Teoría del túnel”, "esta agresión contra el lenguaje literario, esta destrucción de formas tradicionales, tiene la característica propia del túnel, destruye para construir" (Cortázar 2003g: 72). Según la opinión de Cortázar "en la novela no hay fondo y forma; el fondo da la forma, es la forma." (Cortázar 1994a: 231, subrayado por J.C.) A parte de la trama y la acción, que muy a menudo están presentes pero no son imprescindibles en una

\footnotetext{
${ }^{4}$ María Cristina Preciado dedicó un artículo entero a la noción de la apertura en la obra de Cortázar. V. Preciado 2013.

${ }^{5}$ Tanto el amor de Cortázar por la música jazz, como el hecho de que los aspectos del jazz se pueden utilizar como métodos de interpretación de la obra de Cortázar, han impulsado una multitud de estudios escritos sobre la importancia del jazz en la obra del escritor argentino: p. ej. Gordon 1980; Quintana 1980; Soren Triff 1991; Tyler 1996; Martínez Callejo 2000; González Riquelme 2003; Luna 2004; Guelbenzu 2007; Roberts 2009; Dayan \& Orloff 2010; Goialde Palacios 2010; Torés García 2014; González 2015; Ralón 2016; Abras Daneri 2017; Abras Daneri 2018.
} 
novela, las ideas, según Cortázar, representan la característica esencial de una novela, lo contrario al cuento que "pocas veces transmite[n] ideas" (Cortázar 2003f: 642). La razón de esto se puede encontrar en la relación del autor con los personajes que actúan como portadores de ideas en la novela:

El autor de un cuento no se apasiona por sus personajes; vive muy poco tiempo, muy pocas páginas con ellos; los ve entrar y salir, actuar o morir, y eso es todo. Pero una novela es como un gran amor, tiene un despertar, un mediodía, a veces un lento y penoso crepúsculo. (Cortázar 2003f: 643)

Sin embargo, el espacio que la novela ofrece para el desarrollo de sus protagonistas, en el caso de Cortázar no conduce hacia la creación de unos personajes profundamente perfilados en el sentido psicológico, como son los personajes en las novelas de Thomas Mann. Por esa razón, Cortázar dice que sus novelas son las novelas anti-ThomasMann, anti- o contranovelas (Cortázar 2013: 224), porque en realidad en sus novelas ya no existen héroes literarios en el sentido tradicional de la palabra (Cortázar 1994a: 224-225). Cortázar mantiene que en sus novelas no viven personajes literarios, sino sus cómplices:

adviértase que ya no hay personajes en la novela moderna; hay sólo cómplices. Cómplices nuestros, que son también testigos y suben a un estrado para declarar cosas que - casi siempre - nos condenan; de cuando en cuando hay alguno que da testimonio en favor, y nos ayuda a comprender con más claridad la exacta naturaleza de la situación humana de nuestro tiempo. (Cortázar 1994a: 224-225, subrayado por J. C.)

La complicidad de los personajes con el autor revela la necesidad del escritor argentino de establecer comunicación más allá de los límites de la obra literaria. La literatura para Cortázar en este contexto representa un puente hacia el lector (Cortázar 2003c: 874) quien es "el eslabón final del proceso creador, el cumplimiento o el fracaso del ciclo" (Cortázar 1971: 411). Sin embargo, solo un verdadero lector-cómplice puede desempeñar un papel tan importante porque no todos los que leen una novela son los lectores-cómplices. Solo el lector que esté listo para plantear preguntas y buscar respuestas muy probablemente sin éxito, dispuesto también a exponerse y desnudar los rincones más secretos de su alma, puede ser un lector-cómplice. Por otro lado, un lector-hembra solamente busca las respuestas prefabricadas y placeres de lectura tranquilos, y por eso 
nunca puede ser un lector-cómplice. La clasificación de lectores antes mencionada según la cual los lectores se dividen en lectores-cómplices y lectores-hembras aparece por primera vez en la obra maestra de Cortázar, Rayuela, en 1963, pero el escritor decide utilizarla de nuevo en su ensayo poético "Los caminos de un escritor" que presentó en 1980 en Berkeley (v. Cortázar 1994a). Este hecho confirma irrefutablemente que el uso de los términos "el lector-cómplice" y "el lector-hembra" no se debería limitar a la Rayuela, sino que esos vocablos explican la actitud general de Cortázar hacía sus lectores ${ }^{6}$.

Es con la Rayuela que Cortázar empieza interesarse más en profundo por sus lectores y revela la necesidad de que sus lectores sean al mismo tiempo sus compacientes y cómplices, lo que puede interpretarse como primeras señales del interés del autor por las cuestiones sociales más amplias. Desde temprana edad Cortázar se preocupa por los problemas sociales y los grandes acontecimientos históricos europeos, pero se mostró entusiasta y sinceramente devoto de ellos, como él mismo observa irónicamente, participando en fervientes discusiones en los bares de Buenos Aires (Cortázar 2013: 17; Cortázar 2003f: 640). A principios de los años sesenta, con sus primeros viajes a Cuba, Cortázar comienza enfatizar la importancia del componente social en su obra ${ }^{7}$. Su opinión era que "el trabajo del escritor latinoamericano tiene que ser político en el sentido más alto del término, y literario en el sentido más libre y aventurero de la palabra" (Cortázar 2003b: 560). Es por esa razón que los aspectos de compromiso social en la narrativa de Cortázar no se puedan clasificar como declaraciones políticas en forma de panfletos que se relacionan habitualmente con la noción de la literatura comprometida. Precisamente por la falta de elementos abiertamente políticos y propagandistas Cortázar se encontró en el centro de diversas polémicas y lo criticaron por ser insuficientemente revolucionario para un escritor revolucionario. A estas acusaciones de Collazos, Cortázar respondió que la literatura revolucionaria no debe estar orientada a la revolución por su contenido, sino que incluso la manera de escribir debe ser revolucionaria. Cortázar insistía que algunas de sus obras más experimentales, como la novela 62. Modelo para armar, representan al mismo tiempo sus obras

\footnotetext{
${ }^{6}$ Sobre los problemas terminológicos desde la perspectiva feminista en cuanto al término "lector-hembra" con connotación negativa y sobre las disculpas posteriores de Cortázar, véase: Garfield 1975: 108; Garfield, Cortázar 1978: 117; Peavler 1990: 106; Brenes Reyes 2011: 58; Peri Rossi 2014: 69; Vulović 2018: 20.

${ }^{7}$ Para más detalles sobre el activismo social de Cortázar, véase: Kohut 1985-1986; Cédola 1994; Standish 1997; Dellepiane 2003; Orloff 2013; Arias Careaga 2014; Vulović 2017.
} 
políticamente más revolucionarias, porque llevan a cabo "la revolución en su propia esfera, revolución en la palabra y la forma y la narración misma" (Cortázar 1970: 74), porque contribuyen a la liberación de la lengua y de la literatura (Cortázar 1970: 70).

Las cuestiones de la libertad ${ }^{8}$ y de la verdad Cortázar las sitúa en el centro de la escritura socialmente responsable y la tarea del escritor latinoamericano, según él, es: «buscar nuestra identidad latinoamericana, nuestra verdad profunda como pueblos y como individuos, destruyendo máscaras y mentiras, liquidando prejuicios y tabúes» (Cortázar 2003a: 976). Cortázar opina que no se puede ofrecer al pueblo una literatura simplificada, con la justificación que sea más adecuada para amplias masas, porque de este modo su verdad llega a ser simplificada también. Él piensa que la literatura que exija cierto esfuerzo de sus lectores, tiene un alcance incomparablemente mayor que la literatura que subestime a sus lectores (Cortázar 2003d: 766; Cortázar 1971: 411-416). Según Cortázar, la literatura simplificada de contenidos únicamente políticos representa solo un aspecto del ser humano a expensas de todos los demás, y de ese modo le priva de la libertad de realizar la plenitud de sus aspiraciones. Cortázar enuncia que la literatura latinoamericana que no sea solamente un reflejo estético de la vida, sino la vida misma (Cortázar 2003e: 638; Cortázar 1982: 7), debe presentar la totalidad del ser humano.

Siguiendo su deseo de presentar el conjunto de la vida humana, Cortázar dedica una porción significante de su obra y de su pensamiento crítico y teórico a la presencia (o ausencia) de los temas eróticos y la sexualidad en la literatura hispanoamericana9. Él cree que la medida exacta de la libertad de un pueblo y su literatura se refleja precisamente en este campo (Cortázar 1970: 34; Cortázar 1974b: 62). En América Latina lo erótico está presente en la poesía y en la literatura traducida de otros idiomas, pero en la literatura hispanoamericana los intentos de liberarse del puritanismo y los estigmas sociales aparecen todavía muy tímida y esporádicamente (Cortázar 1974b: 82-83). El escritor argentino aboga por la eliminación de todos los tabúes de la literatura y menciona algunos de ellos que todavía existen en la sociedad y literatura argentinas.

\footnotetext{
${ }^{8}$ Saúl Sosnowski incluso considera que la cuestión de la libertad es la fundamental para la obra de Cortázar: "Libertad cultural, libertad e independencia a secas, son términos y valores que subyacen a la crítica y a la obra creativa de Cortázar" (Sosnowski 2003: 25, subrayado por S. S.).

${ }^{9}$ Para más detalles sobre el tema de la sexualidad y lo erótico en las ficciones de Cortázar, véase: Flores 1974: 46; Yurkievich 1977; Safir 1978; Planells 1979; Ruffinelli 1980; Shaw 1982; Puleo 1986; Celis 2002: 45; Ubilluz 2006; Garonzik 2016; Vulović 2018.
} 
Cortázar además afirma que hay unos temas que causan mucho más vergüenza y miedo entre los escritores latinoamericanos que otros y él reconoce el tema da la sodomía como uno de ellos. En un tono bastante humorístico, Cortázar se dirige al lector diciendo: "Ríase, compañero, pero Europa tiene el ano más liberado que usted y eso cuenta en una madurez literaria" (Cortázar 1974b: 74). Según Cortázar, la clave para obtener un nivel más alto de madurez literaria y para escribir sobre temas eróticos se encuentra en la lengua que se utiliza para estos fines. Él piensa que un escritor tiene que "desflorar el idioma" (Cortázar 1974b: 63), liberarse de eufemismos y discurso científico-ginecológico estéril cuando escribe sobre la sexualidad, lo que él mismo hace con maestría mezclando humor, cariño y soltura con temas muy delicados. Además, es necesario que un escritor muestre la sexualidad en su totalidad que supone "la alegría, (...) la ternura, la tristeza, la sencillez, la naturalidad, el amor" (Cortázar 1974b; 71, subrayado por J. C.), que escriba sobre lo erótico de la misma manera que escribe sobre cualquier otro tema, abierta y sinceramente, sin frenos, para que se emancipe la totalidad de la vida social humana.

Los escritos auto-poéticos de Cortázar evidentemente son significativos por las ideas del autor que se encuentran allí. Sin embargo, si se presta atención especial al modo de escribir estos textos de Cortázar, una de estas ideas, la que se refiere a la inexistencia del fondo y forma, al hecho de que en una obra literaria el fondo y la forma sean lo mismo, llega a ser incluso más interesante e importante. Sin renunciar a su sentido del humor particular, la autocrítica y el tono conversacional, en sus escritos poéticos Cortázar implementa los mismos principios por los que lucha. Cuando escribe sobre la liberación del puritanismo en la literatura, Cortázar escribe que tenemos que "desflorar el idioma" (Cortázar 1974b: 63), cuando habla sobre la revolución en la literatura, que necesitamos a "los Che Guevara del lenguaje" (Cortázar 1970: 76), él es el primero en encender la chispa revolucionaria en sus escritos. Por su calidad y captación, los textos del Cortázar-ensayista, del Cortázar-histórico o del Cortázar-teórico-literario no están por debajo de los textos del Cortázarescritor-de-las-obras-de-arte. No obstante, la persuasión de la poética de Cortázar radica en el hecho de que él la pone en marcha en el mismo momento cuando la define, mostrando de ese modo no solo que una literatura así sea posible, sino que ya existe. 


\section{BIBLIOGRAFÍA}

Abras Daneri, Araceli. "Julio Cortázar: el jazz y América”. Catedral Tomada, Vol. 5, Núm. 9 (2017): 536-550. Web. 07 Mar. 2019.

Abras Daneri, Araceli. "El jazz y Cortázar". Álabe, Núm. 18 (2018): S.P. Web. 05 Mar. 2019.

Ames Casas, Paul. "Último Round de Julio Cortázar: cristal de un evento total". Tesis de grado. Pontificia Universidad Javeriana, 2011. Institutional Repository - Pontificia Universidad Javeriana. Web. 17 Sep. 2018.

Arias Careaga, Raquel. Julio Cortázar. De la subversión literaria al compromiso político. Madrid: Sílex Ediciones, 2014. Impreso.

Auerbach, Erich. "Figura". Scenes from the Drama of European Literature, Minneapolis: University of Minnesota Press, 1984: 11-76. Print.

Batres Cuevas, Izara. "Cortázar y París: hacia una poética explícita de su narrativa: Último Round". Tesis de doctorado. Universidad Complutense de Madrid, 2013. E-Prints Complutense. Web. 17 Sep. 2018.

Boldy, Steven. The novels of Julio Cortázar. Cambridge [Eng.]; New York: Cambridge University Press, 1980. Print.

Bongers, Wolfgang. Schrift / Figuren: Julio Cortázars transtextuelle Ästhetik. Tübingen: Stauffenburg, 2000. Druck.

Brenes Reyes, Jaime. "Ontological and Political Search for 'El Hombre Nuevo': Julio Cortázar's Rayuela and Libro de Manuel.". Master Thesis. University of Guelph, 2011. The Atrium. Web. 17 Abr. 2016.

Cédola, Estela. Cortázar: el escritor y sus contextos. Buenos Aires: Edicial, 1994. Impreso.

Celis, Roger. "Erotismo y Muerte; Georges Bataille y Julio Cortázar". Chasqui, Vol. 31, Núm. 1 (2002): 38-49. JSTOR. Web. 11 Ago. 2015.

Cortázar, Julio. "Literatura en la revolución y revolución en la literatura: algunos malentendidos a liquidar". Óscar Collazos et al. (Eds.). Literatura en la revolución y revolución en la literatura (polémica), México: Siglo Veintiuno Editores, 1970: 38-77. Impreso.

Cortázar, Julio. "Algunos aspectos del cuento". Cuadernos Hispanoamericanos, Núm. 255 (1971): 403-406. Biblioteca Virtual Miguel de Cervantes. Web. 13 Sep. 2018.

Cortázar, Julio. "Del cuento breve y sus alrededores". Último round, Vol. 1, 4a edición, Madrid: Siglo XXI de España Editores, 1974a: 59-82. Impreso. 
Cortázar, Julio. "/que sepa abrir la puerta para ir a jugar". Último round, Vol. 2, 4ª edición, Madrid: Siglo XXI de España Editores, 1974b: 5884. Impreso.

Cortázar, Julio. "Cristal con una rosa adentro". Último round, Vol. 2, 4a edición, Madrid: Siglo XXI de España Editores, 1974c: 127-129. Impreso.

Cortázar, Julio. "Realidad y literatura en América Latina". The City College Papers, Núm. 19 (1982): 5-16. Fondo Julio Cortázar. CRLA ARCHIVOS - Centre de Recherches Latino-Américaines-Archivos. Web. 15 Sep. 2018.

Cortázar, Julio. "Situación de la novela”. Obra crítica / 2, Edición de Jaime Alazraki, Madrid: Alfaguara, 1994a: 215-241. Impreso.

Cortázar, Julio. "Para una poética". Obra crítica / 2, Edición de Jaime Alazraki, Madrid: Alfaguara, 1994b: 265-285. Impreso.

Cortázar, Julio. "América Latina y sus escritores". Obras completas. VI Obra crítica, Edición de Saúl Yurkievich con la colaboración de Gladis Anchieri, Barcelona: Galaxia Gutenberg: Círculo de Lectores, 2003a: 975-976. Impreso.

Cortázar, Julio. "El escritor y el lector en América Latina”. Obras completas. VI Obra crítica, Edición de Saúl Yurkievich con la colaboración de Gladis Anchieri, Barcelona: Galaxia Gutenberg: Círculo de Lectores, 2003b: 553-560. Impreso.

Cortázar, Julio. "El escritor y su quehacer en América Latina". Obras completas. VI Obra crítica, Edición de Saúl Yurkievich con la colaboración de Gladis Anchieri, Barcelona: Galaxia Gutenberg: Círculo de Lectores, 2003c: 873-885. Impreso.

Cortázar, Julio. "El intelectual y la política en Hispanoamérica". Obras completas. VI Obra crítica, Edición de Saúl Yurkievich con la colaboración de Gladis Anchieri, Barcelona: Galaxia Gutenberg: Círculo de Lectores, 2003d: 752-766. Impreso.

Cortázar, Julio. "La literatura latinoamericana a la luz de la historia contemporánea". Obras completas. VI Obra crítica, Edición de Saúl Yurkievich con la colaboración de Gladis Anchieri, Barcelona: Galaxia Gutenberg: Círculo de Lectores, 2003e: 626-638. Impreso.

Cortázar, Julio. "Los caminos de un escritor". Obras completas. VI Obra crítica, Edición de Saúl Yurkievich con la colaboración de Gladis Anchieri, Barcelona: Galaxia Gutenberg: Círculo de Lectores, 2003f: 639-650. Impreso.

Cortázar, Julio. “Teoría del túnel. Notas para una ubicación del surrealismo y el existencialismo". Obras completas. VI Obra crítica, Edición de 
Saúl Yurkievich con la colaboración de Gladis Anchieri, Barcelona: Galaxia Gutenberg: Círculo de Lectores, 2003g: 45-125. Impreso. Cortázar, Julio. Clases de literatura: Berkeley, 1980, Madrid: Alfaguara, 2013. Impreso.

Dayan, Peter \& Carolina Orloff. "Finding Rhythm in Julio Cortázar's Los premios". Paragraph, Vol. 33, Issue 2 (2010): 215-229. Edinburgh University Press. Web. 10 Sep. 2018.

Dellepiane, Ángela. "Otra experiencia para lectores «salteados»: «Libro de Manuel»". Nueva narrativa hispanoamericana, Núm. 5 (1975): 17-34. Impreso.

Dellepiane, Ángela B. "La palabra cortazariana: «Abrir la puerta para ir a jugar»". Con Alonso Zamora Vicente: (Actas del Congreso Internacional «La Lengua, la Academia, lo Popular, los Clásicos, los Contemporáneos...»), Vol. II, Alicante: Universidad de Alicante, 2003: 553-567. Biblioteca Virtual Miguel de Cervantes. Web. 10 Sep. 2018. Dickov, Vesna. „Narativna proza Hulija Kortasara“ [La prosa narrativa de Julio Cortázar]. LIK, God. 1, Br. 1 (2015): 107-117. Štampano.

Filer, Malva E. Los mundos de Julio Cortázar. Long Island City, New York, USA: Las Américas Pub. Co., 1970. Impreso.

Flores, Félix Gabriel. "El lirismo metafísico de Julio Cortázar". Cuadernos Hispanoamericanos, Núm. 289-290 (1974): 7-52. Biblioteca Virtual Miguel de Cervantes. Web. 14 Oct. 2014.

Francescato, Martha Paley. "Julio Cortázar y un modelo para armar ya armado". Helmy F. Giacoman (Editor). Homenaje a Julio Cortázar: variaciones interpretativas en torno a su obra, Long Island City, N.Y.: Las Américas, 1972: 365-373. Impreso.

Garfield, Evelyn Picon. Julio Cortázar. New York: Ungar, 1975. Print.

Garfield, Evelyn Picon \& Julio Cortázar. Cortázar por Cortázar. Xalapa, México: Centro de Investigaciones Lingüístico-Literarias, Universidad Veracruzana, 1978. Impreso.

Garonzik, Rebecca Rae. "Beyond Marcuse: Guevara's Influence on the Revolutionary Erotic in Julio Cortázar's Libro de Manuel". A Contracorriente, Vol. 13, Núm. 2 (2016): 287-310. Web. 11 Ene. 2017.

Goialde Palacios, Patricio. "Palabras con swing. La música de jazz en la obra de Julio Cortázar”. Musiker, Núm. 17 (2010): 483-496. Web. 10 Sep. 2018.

Goloboff, Gerardo Mario. "El «hablar con figuras» de Cortázar". Centre de recherches latino-américaines, Université de Poitiers (Ed.). Coloquio Internacional Lo Lúdico y lo Fantástico en la Obra de Cortázar, Vol. 2, Madrid: Editorial Fundamentos, 1986: 241-256. Impreso. 
González, Diego Arturo. "Rayuela: un encuentro con el jazz". La tercera orilla, Núm. 15 (2015). S. P. Web. 15 Sep. 2018.

González Riquelme, Andrés. "La máquina musical en «El perseguidor» de Julio Cortázar". Acta Literaria, Núm. 28 (2003): 33-44. SciELO. Web. 10 Sep. 2018.

Gordon, Samuel. "Algunos aportes sobre crítica y «jazz», en la lectura de «El Perseguidor»". Cuadernos Hispanoamericanos, Núm. 364-366 (1980): 595-608. Biblioteca Virtual Miguel de Cervantes. Web. 05 Mar. 2019.

Guelbenzu, José María. "Julio Cortázar: el jazz y la escritura". Claves de razón práctica, Núm. 171 (2007): 46-51. Impreso.

Harss, Luis. "Julio Cortázar, o la cachetada metafísica”. Los nuestros, Buenos Aires: Editorial Sudamericana, 1966: 252-300. Impreso.

Hartmann, Joan. "La búsqueda de las figuras en algunos cuentos de Cortázar". Revista Iberoamericana, Vol. XXXV, Núm. 69 (1969): 539_ 549. Web. 15 Sep. 2018.

Kerr, Lucile. "Betwixt Reading and Repetition (apropos of Cortázar's 62: A Model Kit)". Carlos J. Alonso (Editor). Julio Cortázar: new readings, Cambridge / New York: Cambridge University Press, 1998: 91-109. Print.

Kohut, Karl. "El escritor latinoamericano en Francia. Reflexiones de Julio Cortázar en torno al exilio". INTI, Núm. 22/23 (1985-1986): 263280. JSTOR. Web. 05 Sep. 2014.

Lobo Pedreros, Olga. "La poética hermeneútica de Julio Cortázar: 62 Modelo para armar: novela especular". Thèse de doctorat. Université de Poitiers, 2004. Microfilme.

Luna, Rafael. "Cortázar y el jazz". Revista de la Universidad de México, Núm. 1 (2004): 92-94. Web. 07 Mar. 2019.

Martínez Callejo, César. "Los cronopios no beben Coca-cola pero escuchan jazz: (imagen de la cultura norteamericana en Julio Cortázar)”. José Carlos González Boixo et al. (Eds.). Actas del Congreso Internacional Literatura de las Américas, 1898-1998: León, 12-16 de octubre de 1998, Vol. I, León: Universidad de León, 2000: 355-366. Biblioteca Buleria: Repositorio Institucional Abierto. Web. 07 Mar. 2019.

Orloff, Carolina. "La vuelta al día en ochenta mundos and Último Round: The Politics of Julio Cortázar's Collage Books". Bulletin of Spanish Studies, Vol. 90, No. 2 (2013): 229-253. Taylor \& Francis Online. Web. 15 Dic. 2014.

Peavler, Terry J. Julio Cortázar. Boston: Twayne, 1990. Print.

Peri Rossi, Cristina. Julio Cortázar y Cris. Palencia: Cálamo, 2014. Impreso. 
Planells, Antonio. Cortázar: metafísica y erotismo. Madrid: J. Porrúa Turanzas, 1979. Impreso.

Preciado, María Cristina. "Notas para una poética de la escritura en Julio Cortázar: Nociones en torno a su poética existencial". Sincronía, núm. 63 (2013): 1-33. Redalyc. Web. 10 Sep. 2018.

Preciado, María Cristina. "Figura: una poética de la imagen en la escritura de Julio Cortázar". Tésis doctoral. Universitat Pompeu Fabra, 2014. Tesis Doctorals en Xarxa. Web. 13 Sep. 2018.

Prego, Omar. La fascinación de las palabras: conversaciones con Julio Cortázar. Barcelona: Muchnik, 1985. Impreso.

Puleo, Alicia Helda. "La sexualidad fantástica". Centre de recherches latinoaméricaines, Université de Poitiers (Ed.). Coloquio Internacional Lo Lúdico y lo Fantástico en la Obra de Cortázar, Vol. 1, Madrid: Editorial Fundamentos, 1986: 203-212. Impreso.

Quintana, Juan. "Cortjazzar". Cuadernos Hispanoamericanos, Núm. 364366 (1980): 265-269. Biblioteca Virtual Miguel de Cervantes. Web. 05 Mar. 2019.

Ralón, Laureano. "Cortázar y el swing". Estudios de Teoría Literaria, Año 5, Núm. 10 (2016): 15-25. Web. 13 Sep. 2018.

Roberts, Nicholas. "Subverted Claims: Cortázar, Artaud, and the Problematics of Jazz". The Modern Language Review, Vol. 104, No. 3 (2009): 730-745. JSTOR. Web. 20 Oct. 2014.

Ruffinelli, Jorge. "Cortázar: Erotismo y alegría". Cuadernos Hispanoamericanos, Núm. 364-366 (1980): 333-341. Biblioteca Virtual Miguel de Cervantes. Web. 05 Mar. 2019.

Safir, Margery A. "An Erotics of Liberation: Notes on Transgressive Behavior in Hopscotch and Libro de Manuel". Jaime Alazraki \& Ivar Ivask (Eds.). Final Island, Norman: University of Oklahoma Press, 1978: 84-96. Print.

Salmones Castaneda, Haydeé Gisela. "62 / Modelo para armar: una teoría de la novela según Morelli." Tésis inédita. Universidad Nacional Autónoma de México, 2013. Web. 15 Ene. 2017.

Scholz, László. El arte poética de Julio Cortázar. San Antonio de Padua, Argentina: Ediciones Castañeda, 1977. Impreso.

Shaw, Donald L. "Notes on the presentation of sexuality in the modern Spanish-American novel". Bulletin of Hispanic Studies, Vol. 59, No. 3 (1982): 275-282. ProQuest. Web. 31 Ago. 2014.

Sicard, Alain. "Figura y novela en la obra de Julio Cortázar". Pedro Lastra (Editor). Julio Cortázar, Madrid: Taurus, 1981: 225-240. Impreso. 
Soren Triff, Eduardo. "Improvisación musical y discurso literario en Julio Cortázar”. Revista Iberoamericana, Núm. 155-156 (1991): 657663. JSTOR. Web. 20 Oct. 2014.

Sosnowski, Saúl. "Prólogo. Cortázar crítico: la razón del deseo". Julio Cortázar. Obras completas VI. Obra crítica, Edición de Saúl Yurkievich con la colaboración de Gladis Anchieri, Barcelona: Galaxia Gutenberg: Círculo de Lectores, 2003: 9-37. Impreso.

Standish, Peter. "Los compromisos de Julio Cortázar". Hispania, Vol. 80, No. 3 (1997): 465-471. JSTOR. Web. 06 May. 2014.

Torés García, Alberto. "Julio Cortázar escribe partituras al tiempo que toca novelas". Sur, Núm. 4 (2014): 67-73. Dialnet. Web. 17 Sep. 2018.

Tyler, Joseph. "Cortázar: jazz y literatura”. INTI, Núm. 43-44 (1996): 147155. JSTOR. Web. 20 Oct. 2014.

Ubilluz, Juan Carlos. Sacred eroticism: Georges Bataille and Pierre Klossowski in the Latin American erotic novel. Lewisburg [Pa.]: Bucknell University Press, 2006. Print.

Yurkievich, Saúl. "Eros ludens (juego, amor, humor según Rayuela)". Escritura: Teoría y crítica literarias, Núm. 3 (1977): 133-147. Impreso.

Zeppegno, Giuliana. "A pesar de Morelli: 62/Modelo para armarde Julio Cortázar entre figuras y causalidad onírica". Anales de Literatura Hispanoamericana, Núm. 41 (2012): 321-344. Web. 23 Nov. 2014.

Vulović, Ksenija. „Književnost u revoluciji i revolucija u književnosti: Manuelova knjiga Hulija Kortasara" [Literatura en revolución y revolución en literatura: Libro de Manuel de Julio Cortázar]. Književna istorija, God. 49, Br. 163 (2017): 307-326. Štampano.

Vulović, Ksenija. „Narativ ljubavi u romanima Hulija Kortasara i Milorada Pavića“ [La narración de amor en novelas de Julio Cortázar y Milorad Pavić]. Doktorska disertacija. Univerzitet u Beogradu, 2018. Veb. NaRDus - Nacionalni repozitorijum disertacija u Srbiji. 15 Mar. 2019. 


\title{
JULIO CORTÁZAR'S EXPLICIT POETICS
}

\begin{abstract}
Summary
Julio Cortázar exposes his explicit poetics in numerous essays, critical and theoretical studies that he wrote and published throughout his life. The complex question of the relationship between reality and fantastic literature presents a topic of great importance both for Cortázar's literary creation, and for the so-called Latin American "boom". Cortázar is against the nineteenthcentury realism that doesn't include that more profound and secret part of life, and he announces the idea of representing the entire reality in literature. In his essays, Cortázar closely ties the question of reality to different ways of presenting it in short stories and novels. Through a series of accurate and vivid comparisons, Cortázar elaborates his theory of the short story and the novel. Although he insists on writer's responsibility for the success of his work, Cortázar emphasizes the importance of an active reader. In this sense, the question of the social commitment of literature emerges as a central issue. Cortázar argues that a truly revolutionary work of art doesn't necessarily have to focus on political and revolutionary content, but rather on literary innovation. According to Cortázar, the possibility of writing about erotic topics present another form of literary revolution that should be carried out so that Spanish American literature encompasses every aspect of the human condition and so that the totality of human social life is emancipated in literature.
\end{abstract}

Keywords: Julio Cortázar (1914-1984), explicit poetics, short story, novel, literary revolution. 